\title{
Combination of circulating miR-145-5p/miR-191-5p as biomarker for breast cancer detection
}

\author{
Yeldar Ashirbekov ${ }^{\text {Corresp., } 1}{ }^{1}$, Arman Abaildayev ${ }^{1}$, Nazgul Omarbayeva ${ }^{2}$, Dauren Botbayev ${ }^{1}$, Ayaz Belkozhayev ${ }^{1}$, Anel \\ Askandirova $^{2}$, Alena Neupokoyeva ${ }^{3}$, Gulzhakhan Utegenova ${ }^{4}$, Kamalidin Sharipov ${ }^{1}$, Nagima Aitkhozhina ${ }^{1}$ \\ 1 M. Aitkhozhin Institute of Molecular Biology and Biochemistry, Almaty, Kazakhstan \\ Kazakh Research Institute of Oncology and Radiology, Almaty, Kazakhstan \\ 3 Almaty Branch of National Center for Biotechnology, Almaty, Kazakhstan \\ 4 South Kazakhstan State Pedagogical University, Shymkent, Kazakhstan \\ Corresponding Author: Yeldar Ashirbekov \\ Email address: eldarasher@mail.ru
}

Background: Breast cancer (BC) is the most common cancer among women worldwide. At present, there is a need to search for new, accurate, reliable, minimally invasive and cheap biomarkers in addition to existing methods for the diagnosis and prognosis of BC. The main goal of this study was to test the diagnostic value of six circulating miRNAs in Kazakh women.

Materials and methods: TaqMan-based miRNA profiling was conducted using plasma specimens from $35 \mathrm{BC}$ women patients and 33 healthy women samples (control group).

Results: The level of all seven miRNAs (including endogenous control) normalized by synthetic celmiR-39 were significantly elevated in the group of BC patients. Normalization using miR-222-3p as endogenous control reduced differences in level of miRNAs between groups; as a result, only three miRNAs were significantly upregulated in the group of BC patients - miR-145-5p $(P=6.5 e-12)$, miR-191-5p ( $P=3.7 e-10)$ and miR-21-5p ( $P=0.0034)$. Moreover, ROC analysis showed that the use of miR-145-5p and miR-191-5p, both individually ( $A U C=0.931$ and 0.904 , respectively) or in combination $(A U C=0.984)$, allows to accurately differentiate BC patients from healthy individuals.

Conclusions: Two plasma miRNAs - miR-145-5p and miR-191-5p - are potential biomarkers for diagnosis of $\mathrm{BC}$ in the Kazakh population. The findings need to be further substantiated using a more representative sample. 
1 Combination of circulating miR-145-5p/miR-191-5p as

2 biomarker for breast cancer detection

3

4

5

6

7

8

9

12

\section{Yeldar Ashirbekov ${ }^{1}$, Arman Abaildayev ${ }^{1}$, Nazgul Omarbayeva ${ }^{2}$, Dauren Botbayev ${ }^{1}$, Ayaz} Belkozhayev $^{1}$, Anel Askandirova ${ }^{2}$, Alena Neupokoyeva ${ }^{3}$, Gulzhakhan Utegenova ${ }^{4}$, Kamalidin Sharipov $^{1}$, Nagima Aitkhozhina ${ }^{1}$

${ }^{1}$ M. Aitkhozhin Institute of Molecular Biology and Biochemistry, Almaty, Kazakhstan

${ }^{2}$ Kazakh Research Institute of Oncology and Radiology, Almaty, Kazakhstan

${ }^{3}$ Almaty Branch of National Center for Biotechnology, Almaty, Kazakhstan

${ }^{4}$ South Kazakhstan State Pedagogical University, Shymkent, Kazakhstan

Corresponding Author:

Ashirbekov Yeldar ${ }^{1}$

86 Dosmukhamedov Str., Almaty, 050012, Kazakhstan

Email address: eldarasher@mail.ru

\section{Abstract}

Background: Breast cancer (BC) is the most common cancer among women worldwide. At present, there is a need to search for new, accurate, reliable, minimally invasive and cheap biomarkers in addition to existing methods for the diagnosis and prognosis of $\mathrm{BC}$. The main goal of this study was to test the diagnostic value of six circulating miRNAs in Kazakh women. Materials and methods: TaqMan-based miRNA profiling was conducted using plasma specimens from $35 \mathrm{BC}$ women patients and 33 healthy women samples (control group). Results: The level of all seven miRNAs (including endogenous control) normalized by synthetic cel-miR-39 were significantly elevated in the group of BC patients. Normalization using miR$222-3 p$ as endogenous control reduced differences in level of miRNAs between groups; as a result, only three miRNAs were significantly upregulated in the group of BC patients - miR-145$5 \mathrm{p}(\mathrm{P}=6.5 \mathrm{e}-12)$, miR-191-5p $(\mathrm{P}=3.7 \mathrm{e}-10)$ and miR-21-5p $(\mathrm{P}=0.0034)$. Moreover, ROC analysis showed that the use of miR-145-5p and miR-191-5p, both individually (AUC $=0.931$ and 0.904 , respectively) or in combination $(\mathrm{AUC}=0.984)$, allows to accurately differentiate $\mathrm{BC}$ patients from healthy individuals.

Conclusions: Two plasma miRNAs - miR-145-5p and miR-191-5p - are potential biomarkers for diagnosis of $\mathrm{BC}$ in the Kazakh population. The findings need to be further substantiated using a more representative sample.

\section{Introduction}

Breast cancer (BC) is the most commonly diagnosed cancer type in women around the world. Just like most cancers, early $\mathrm{BC}$ is asymptomatic. This has resulted in late detection of the 
40 disease, at which point no therapy is very effective (Höfelmann, Anjos \& Ayala, 2014).

41 Mammographic screening of women, in the age range the most at risk to breast cancer, did make

42 the tumor detection at early stages more common and therefore, caused significant reduction in

43 mortality (Onega et al., 2016; Wang, 2017). However, mammography shows a significant

44 number of false positives in women with dense breasts, especially at a younger age. In this

45 regard, mammography screening is confidently recommended for women over 50 years old, 46 although women aged 40-50 years are also at risk of BC (McDonald et al., 2015; Nelson et al.,

47 2016; Phi et al., 2018). Various molecular subtypes of BC that require different therapy

48 (EBCTCG, 2015; Guerrero-Zotano \& Arteaga, 2018; Lee \& Seo, 2018), individual patient

49 susceptibility to drugs and side effects from drugs (Potosky et al., 2015; Greenlee et al., 2017;

50 Moo et al., 2018) and the development of drug resistance (Li et al., 2020; Zhong et al., 2020)

51 make treatment of this disease more difficult and complicated. The listed difficulties indicate the

52 need for study of new biomarkers that can help in the early detection, diagnosis and prognosis of

53 BC.

54 Nowadays miRNAs are promising markers for early diagnosis and prognosis of tumors. miRNAs

55 are a large class of small non-coding RNAs that function as negative regulators of most genes in

56 the genome and are involved in important biological processes, such as development,

57 differentiation, apoptosis, proliferation, etc. (Jansson \& Lund, 2012). Many studies have

58 highlighted differential expression of certain miRNAs in several cancer types, including BC

59 (Acunzo et al., 2015; Aggarwal, Priyanka \& Tuli, 2020).

60 The property of miRNAs that they can be detected in both tumor cells and biological fluids (in a

61 cell-free form) serves as a major advantage for using these molecules over other oncogenic

62 biomarkers. miRNAs directly enter the bloodstream from primary or metastatic tumors by active secretion, apoptosis or necrosis, and thus changes in the amount of circulating miRNAs can reflect the pathological process (Schwarzenbach, 2017; Sun et al., 2018). In this regard, the level of miRNA-marker can be determined in a minimally invasive way. High stability of miRNA in biological fluids also makes them a very suitable choice as cancer biomarkers (Grasedieck et al., 2012; Glinge et al., 2017). Several miRNAs have been revealed to contribute to the pathological mechanisms of $\mathrm{BC}$ progression and many of them have been recommended by previous research studies as diagnostic or prognostic markers (McGuire, Brown \& Kerin, 2015; Stückrath et al., 2015; Zhang et al. 2015; Schwarzenbach, 2017; Hamam et al., 2017; Nassar, Nasr \& Talhouk, 2017; Shao et al., 2019). The main limitation of currently existing serum biomarkers, including the best of them CA15-3 and CEA, as a marker of BC is the lack of sensitivity for patients with early disease (Duffy, Evoy \& McDermott, 2010); miRNA-markers seem to have no such limitations (Schwarzenbach, 2017). It is known that there are some ethnic differences in the pathogenesis of breast cancer (Nakshatri, Anjanappa \& Bhat-Nakshatri, 2015; Özdemir \& Dotto, 2017; Wu et al., 2020), which is also true for the applicability of miRNAs as markers of BC (Zhao et al., 2010; Nassar et al., 2017; Wu et al., 2020). For this reason, miRNA-markers need to be validated for specific ethnic groups. 
The aim of our study was to test the diagnostic value of six circulating miRNAs recommended previously as plasma/serum markers of BC: miR-145-5p (Ng et al., 2013), miR-21-5p (Adhami et al., 2018), miR-210-3p (Jung et al., 2012), miR-29c-3p (Zhang et al., 2015), miR-16-5p (Usmani et al., 2017) and miR-191-5p (Mar-Aguilar et al., 2013) among Kazakh women. To do so, we compared plasma levels of the miRNAs between age-matched BC patients $(n=35)$ and healthy women $(n=33)$ from Almaty and Almaty region in Kazakhstan.

\section{Materials \& Methods}

\section{Subjects}

Venous blood of 35 Kazakh women with primary BC was collected at the Kazakh Research Institute of Oncology and Radiology, Almaty, Kazakhstan before therapy in 2019. All patients analyzed had histologic proven BC. The average age of patients was $52.6 \pm 11.66$. Venous blood of 33 healthy Kazakh women was collected in the Karasai central district hospital in the Almaty region, Kazakhstan in 2019. All controls underwent mammography and were over 40 years old. The average age of the control group was 53.0 \pm 7.61 . Clinicopathological characteristics of BC patients and control group are presented in Table 1. The study was carried out in compliance with the principles of the Helsinki Declaration, and approved by the local ethics committee of the M. Aitkhozhin Institute of Molecular Biology and Biochemistry, Almaty, Kazakhstan (approval number 185/01-02). All participants provided written informed consent for the use of biomaterials in this study.

\section{Plasma preparation}

Blood was collected in vacuum tubes with sodium citrate, which showed considerable miRNA yield in preliminary tests. Blood was stored at $4^{\circ} \mathrm{C}$ and plasma was obtained within 8 hours after blood sampling. To obtain plasma, the blood was centrifuged at $1000 \mathrm{~g}$ for $15 \mathrm{~min}$ at $4^{\circ} \mathrm{C}$; the upper aqueous phase was transferred to a fresh tube and centrifuged at $2500 \mathrm{~g}$ for $15 \mathrm{~min}$ at $4^{\circ} \mathrm{C}$. The resulting plasma was divided into aliquots and stored at $-70^{\circ} \mathrm{C}$ until the isolation of miRNA step. Before being examined, the plasma was subjected to one freeze-thaw cycle.

\section{Isolation of RNA}

Isolation of total RNA from $200 \mu$ of plasma was performed utilizing technique previously developed by (Zununi Vahed S. et al., 2016) with minor modifications. Briefly, deproteinization was carried out according to the standard Trizol method. Then, to precipitate RNA, an equal volume of $2.5 \mathrm{M}$ lithium chloride and two volumes of cold ethanol were added and incubated overnight at $-70^{\circ} \mathrm{C}$, then centrifuged for $16000 \mathrm{~g}$ for $20 \mathrm{~min}$ at $4^{\circ} \mathrm{C}$. The pellets was dried and dissolved in $50 \mu \mathrm{L}$ of DEPC water, incubating for $5 \mathrm{~min}$ at $65^{\circ} \mathrm{C}$. At the stage of Trizol treatment, $20 \mathrm{fmol}$ of synthetic cel-miR-39 was added to the sample. The resulting total RNA sample was stored at $-70{ }^{\circ} \mathrm{C}$ until use.

\section{Obtaining cDNA and quantitative PCR}

Reverse transcription and quantitative PCR was performed using primers and probes from TaqMan MicroRNA Assay (Applied Biosystems, USA). cDNA was obtained using TaqMan MicroRNA Reverse Transcription Kit reagents (Applied Biosystems) according to the 
119 manufacturer's protocol. Quantitative PCR was performed in triplicates using TaqMan Universal 120 Master Mix II with UNG reagents (Applied Biosystems) under the conditions recommended by

121 the manufacturer on the StepOnePlus Real-Time PCR System (Applied Biosystems).

122 Quantitative data was normalized to the level of exogenous spike-in control cel-miR-39 and 123 endogenous control miR-222-3p.

124 Statistical analysis

125 Primary processing of the results was carried out in StepOne Software and ExpressionSuite

126 Software. The suitability of endogenous control was evaluated using the NormFinder (Andersen,

127 Jensen \& Orntoft, 2004) and GeNorm (Vandesompele et al., 2002) programs. Relative

128 quantification is carried out using the comparative $\mathrm{Ct}(\Delta \Delta \mathrm{Ct})$ method with modifications as

129 described in the paper (Königshoff $\mathrm{M}$ et al., 2009). Relative transcript abundance is expressed in

$130 \Delta \mathrm{Ct}$ values $\left(\Delta \mathrm{Ct}=\mathrm{Ct}_{\text {reference }}-\mathrm{Ct}_{\text {target }}\right) . \Delta \Delta \mathrm{Ct}$ value $\left(\Delta \Delta \mathrm{Ct}=\Delta \mathrm{Ct}_{\mathrm{BC}}-\Delta \mathrm{Ct}_{\text {control }}\right)$ was considered as

$131 \log _{2}$ fold change.

132 Statistics were performed in the Jamovi program (https://www.jamovi.org). Statistical

133 significance of the differences in $\Delta \mathrm{Ct}$ between the groups was calculated using the two-tailed

134 Mann-Whitney $\mathrm{U}$ test. $\mathrm{P}<0.05$ was considered statistically significant. Due to the explorative

135 nature of the study no adjustment for multiple testing was performed. The characteristics of the

136 markers were evaluated by ROC analysis using the web-tool easyROC (Goksuluk et al., 2016),

137 and Jamovi. Youden's index method was used to calculate optimal cut-off points.

138

139

\section{Results}

\section{Endogenous control selection}

141 To select the best endogenous control, we evaluated the concentration stability of analyzed 142 miRNAs in our sample with the help of NormFinder and GeNorm programs. According to

143 NormFinder, the three best (the lowest) stability values were shown for miR-21-5p, miR-222-3p and miR-29c-3p (Fig. 1A). According to GeNorm, miR-222-3p and miR-29c-3p are the best internal controls for our sample (Fig. 1B). Thus, there are two miRNAs on the overlap of the results of two programs: miR-222-3p and miR-29c-3p.

147 Unlike NormFinder, GeNorm does not recommend using miR-21-5p. Also, although

148 NormFinder showed the best stability value for miR-21-5p, intragroup variation in the BC patient group was the largest. This may indicate the heterogeneity of the group and does not exclude the existence of an association between circulating miR-21-5p concentration and some clinicopathological parameter. These considerations, as well as the fact that circulating miR-21$5 \mathrm{p}$ has most often been found to be dysregulated in BC (Schwarzenbach, 2017; Adhami et al., 2018), prompted us to abandon it as an endogenous control.

154 One of the important criteria when choosing endogenous control is their relative abundance. It 155 seems to us that miR-29c-3p is not abundant enough for this role ( $\mathrm{Ct}$ mean 34.6). Taking into 156 account all the mentioned above, we decided to use miR-222-3p as single endogenous control for 157 our study.

158 The level of miRNA in the plasma of $\mathrm{BC}$ patients in comparison with the control group 
159 The Ct values of the analyzed miRNAs in two groups relative to the spike-in control cel-miR-39

160

161

162

163

164

165

166

167

168

169

170

171

172

173

174

175

176

177

178

179

180

181

182

183

184

185

186

187

188

189

190

191

192

193

194

195

196

197

198

level are shown in Figure 2A. The concentration of all miRNAs, including miR-222-3p (used later as endogenous control), was significantly elevated in the plasma of $\mathrm{BC}$ patients compared to healthy controls. $\log _{2}$ fold changes higher than one are obtained for miR-145-5p (2.36), miR191-5p (1.87) and miR-21-5p (1.35) (Table 2).

When quantitative data were normalized to miR-222-5p, the levels of miR-145-5p, miR-191-5p and miR-21-5p in the $\mathrm{BC}$ group were significantly increased compared to healthy controls (Fig. 2B). Differences between groups in miR-16-5p, miR-210-3p, and miR-29c-3p concentrations were not significant. Compared to cel-miR-39 normalization, $\log _{2}$ fold change significantly decreased: only one miRNA exceeded one - miR-145-5p (1.38). Relative to the endogenous control, the level of cel-miR-39 was significantly lower in the group of BC patients $(\Delta \Delta \mathrm{Ct}=$ $0.98, \mathrm{P}=0.0004)$ with a wider range of $\Delta \mathrm{Ct}$ values compared to the control group.

\section{Associations with clinicopathological parameters}

The results of comparisons between groups with different clinicopathological characteristics are presented in Table 3. When normalized to endogenous control miR-222-3p, the level of miR$145-5 p$ was significantly higher $(\mathrm{P}=0.043)$ and the level of miR-191-5p was significantly lower $(\mathrm{P}=0.006)$ in patients with HER2 positive tumor compared to patients with HER2 negative tumor. The level of miR-21-5p in patients with high Ki-67 ( $\geq 20 \%)$ was significantly higher compared to patients with low Ki-67 ( $\mathrm{P}=0.003)$. The level of miR-210-3p and miR-145-5p in patients with poorly differentiated tumor (grade G3) were significantly higher compared to patients with moderately differentiated tumor (grade G2) $(P=0.007$ and 0.033 , respectively). In the group of BC patients, levels of miR-145-5p and miR-21-5p were significantly higher in women with early menarche compared to women with late menarche $(\mathrm{P}=0.009$ and 0.022 , respectively). In the control group, the level of miR-21-5p in women with two or less children was significantly higher compared to women with more than two children $(\mathrm{P}=0.011)$. In the control group, the level of miR-29c-3p in women over 50 years old was significantly lower compared to women younger than or 50 years old $(\mathrm{P}=0.008)$. In the control group, the level of miR-191-5p in women with a positive family history of cancer was significantly lower compared to women without it $(\mathrm{P}=0.029)$. Differences in the level of the analyzed miRNAs between the groups, categorized by other clinicopathological parameters were not significant.

We also found statistically significant differences in the distribution of women with early and late menarche between $\mathrm{BC}$ and control groups $(\mathrm{P}=0.023, \mathrm{OR}=3.59,95 \% \mathrm{CI}$ : 1.26-10.18), and an inverse correlation between the level of Ki-67 and the age of BC patients (Spearman's rho = $0.507, \mathrm{P}=0.0019$ ).

We did not consider differences between groups divided by clinicopathological parameters based on data normalized to spike-in cel-miR-39, due to doubtful results (see Discussion for details).

\section{ROC analysis}

To test the ability of our miRNAs to distinguish BC patients from healthy individuals, we performed a ROC analysis, the results are presented in Table 4 . When normalized to cel-miR-39, the largest area under the ROC curve (AUC) was obtained for miR-145-5p (0.932); miR-191-5p

PeerJ reviewing PDF | (2020:06:49902:2:0:NEW 8 Nov 2020) 
199

200

201

202

203

204

205

206

207

208

209

210

211

212

213

214

215

216

217

218

219

220

221

222

223

224

225

226

227

228

229

230

231

232

233

234

235

236

237

238

and miR-21-5p were far behind with values close to each other ( 0.868 and 0.842 , respectively) (Fig. 3A). AUC for the remaining 4 miRNAs was lower than 0.8 (Fig. 3B). Using combination models of the three best markers did not increase at least a hundredth of the best individual AUC. When normalized to miR-222-3p, only three miRNAs, that showed significant differences in concentration between BC patients and controls, were tested for suitability as diagnostic markers. Although $\log _{2}$ fold change was significantly reduced relative to cel-miR-39 normalization, the AUC for miR-145-5p was the same 0.932, and for miR-191-5p even increased and amounted to 0.904 (Fig. 3C). The diagnostic effectiveness of miR-21-5p significantly decreased to AUC $=$ 0.705. The combination of miR-145-5p and miR-191-5p in one model made it possible to increase AUC to 0.984 (Fig. 3D) with the highest specificity, good sensitivity (0.943) and accuracy of separation (97\%). The addition of miR-21-5p to this combination did not lead to changes in indicators.

We also tested the ability of miRNAs to separate BC patients according to clinicopathological parameters. ROC analysis showed that using miR-145-5p and miR-191-5p it was possible to distinguish patients with HER2 negative tumors from patients with HER2 positive tumors with $58 \%$ and $74 \%$ accuracy, respectively; using miR-21-5p it was possible to divide patients into low and high Ki-67 groups ( $<20 \%$ vs $\geq 20 \%$ ) with $83 \%$ accuracy; using miR-145-5p and miR-210-3p it was possible to distinguish patients with moderately differentiated and poorly differentiated tumors with $92 \%$ and $74 \%$ accuracy, respectively.

\section{Discussion}

When planning the study, in accordance with literature, we selected 5 miRNAs as candidate markers (miR-21-5p, miR-145-5p, miR-210-3p, miR-222-3p and miR-29c-3p), one miRNA as candidate marker or endogenous control (miR-16-5p), one miRNA as endogenous control (miR191-5p), and one miRNA as exogenous spike-in control (cel-miR-39). However, for the reasons stated below, we decided not to use the spike-in control and chose miR-222-3p as the endogenous control.

When working with bio-fluids, the amount of input biomaterial is easily standardized by the specified volume of the sample, thereby it is possible to take into account the differences that arise during RNA isolation. This is achieved by adding to the sample a certain dose of synthetic miRNA at the step of lysis (Kroh et al., 2010). The lack of reliable and universally accepted endogenous control for miRNA data normalization (Schwarzenbach et al., 2015) determines the relevance of using a spike-in control. Therefore, we first tested spike-in control normalization method.

When we used cel-miR-39 as reference, the average $\Delta \mathrm{Ct}$ values for all 7 miRNAs in BC patients were significantly higher than in controls. These results seem suspicious, although it is possible that they reflect the actual difference between compared groups. Second explanation: blood specimens of the compared groups differed in the degree of hemolysis, although plasma with visually distinct hemolysis was excluded from the analysis in advance. However, Appierto et al. showed that the initial stages of hemolysis are visually indistinguishable (Appierto et al., 2014). 
239 In our case, the level of miR-16-5p, which is considered as a marker of hemolysis (Pizzamiglio 240 et al., 2017), varied less in comparison with other miRNAs. The third explanation: two groups 241 differed in the content of plasma proteins and lipids associated with miRNA, which may affect 242 the efficiency of miRNA isolation, as suggested by (Sourvinou, Markou \& Lianidou, 2013).

243 They found that the Trizol method yielded a reduced amount of spike-in cel-miR-39 compared to 244 endogenous miR-21. In our case, the average $\mathrm{Ct}$ value for cel-miR-39 in the group of BC patients 245 was significantly lower than that in the control group $(\mathrm{P}=0.003)$, but for targeted miRNAs the 246 difference was even more considerable. The obtained data indicate better efficiency of RNA 247 isolation in the group of BC patients, but it is unclear whether the yield of the added synthetic 248 cel-miR-39 and endogenous miRNA in each of the two groups is equal. Due to the ambiguity in 249

250 251

252

253

254

255

256

257

258

259

260

261

262

263

264

265

266

267

268

269

270

271

272

273

274

275

276

277

278 using column-based RNA isolation methods would solve this problem, as shown by (Sourvinou, Markou \& Lianidou, 2013).

Since the spike-in control was inappropriate, we evaluated the concentration stability of endogenous miRNAs to determine its suitability as an internal control. Surprisingly, both initial candidates for reference, miR-191-5p and miR-16-5p, were inferior in stability to other miRNAs. Based on an analysis of concentration stability of our miRNA, and also taking into account the relative abundance of transcripts, we chose miR-222-3p as reference, although initially we selected it as target miRNA for the study in accordance with literature screening (Hu et al., 2012; Song et al., 2017; Kim et al., 2019). Previously, this miRNA was already used as a reference in such studies (Tay et al., 2017). After replacing spike-in cel-miR-39 by endogenous miR-222-3p the difference in the target miRNAs level between the two groups considerably decreased, and as a result, the number of dysregulated miRNAs was reduced to three. Despite this, according to the ROC analysis, the ability of miR-145-5p to distinguish BC patients from controls remained the same; for miR-191-5p it even increased; and the combination of the two made it possible to further improve the separation efficiency. In addition, based on these data, we found associations with clinicopathological parameters for some miRNAs. These arguments suggest that we selected the endogenous control correctly, and our results reflect the real state of things. miR-191-5p is probably the most commonly used as endogenous control in quantitative studies of circulating miRNAs. To date, there is evidence of important role of miR-191 in tumorigenesis and its dysregulation in a wide range of cancers, including BC (Gao et al., 2017; Zhang et al., 2018). Two studies showed the association of circulating miR-191 with BC ( $\mathrm{Ng}$ et al., 2013; Mar-Aguilar et al., 2013). In agreement with these data, we also found a significant upregulation of circulating miR-191-5p in BC patients compared to healthy women. In addition, the concentration of miR-191-5p differed in plasma of BC patients depending on HER-2 status of the tumor. miR-16-5p has also been frequently used previously as an endogenous control (McDermott, Kerin \& Miller, 2013; Donati, Ciuffi \& Brandi, 2019). At the same time, several studies report about increased miR-16-5p concentrations in plasma of BC patients compared to healthy controls (Hu et al., 2012; Ng et al., 2013; Stückrath et al., 2015; Usmani et al., 2017). A meta-analysis of 
279 the diagnostic and prognostic value of miR-16 showed that its use as a biomarker is more 280 applicable in Asian populations (Cui, 2015). Our data are not consistent with the aforementioned 281 studies: we found no significant differences in plasma levels of miR-16-5p between breast cancer 282 patients and the controls in the Kazakh population.

283 miR-145-5p showed the most significant association with BC in our study. This miRNA inhibits 284 the expression of certain oncogenes and thus acts as a tumor suppressor (Sachdeva et al., 2009).

285 In accordance with this concept, most previous studies reported about reduced level of 286 circulating miR-145 in BC patients compared to controls (Ng et al., 2013; Kodahl et al., 2014; $287 \mathrm{Hu}$ et al, 2015). In contrast, in the aforementioned study, Mar-Aguilar et al. found elevated mir288 145-5p level in the serum of BC patients (Mar-Aguilar et al., 2013), which is consistent with our 289

290

291

292

293

294

295

296

297

298

299

300

301

302

303

304

305

306

307

308

309

310

311

312

313

314

315

316

317 data. Thus, according to the identified associations of miR-145-5p and miR-191-5p, our Kazakh population is similar to the Mexican one, and differs from other studied populations. Our results in comparison with published data confirm the thesis that the applicability of the miRNA-marker needs to be verified for certain ethnic group. The revealed differences in plasma miR-145-5p concentration between $\mathrm{BC}$ patients with early and late menarche may help to further understand the role of this miRNA in the pathogenesis of $\mathrm{BC}$.

The most frequently mentioned circulating miRNA in association with $\mathrm{BC}$ is miR-21-5p (Schwarzenbach, 2017; Adhami et al., 2018). We also confirm this association in the Kazakh population. The NormFinder showed a wide range of miR-21-5p variation in the $\mathrm{BC}$ patient group, which indicates the heterogeneity of this group. Indeed, we found significant differences in miR-21-5p level between groups separated by some clinicopathological parameters. We found its significantly increased concentration in the plasma of BC patients with high Ki-67, which is consistent with the data that miR-21 promotes BC proliferation (Qiu et al., 2018; Wang et al., 2019). Early menarche and reduced breastfeeding are considered as risk factors for BC (Jeong et al., 2017; Khalis et al., 2018). We found associations of both factors with elevation of miR-21-5p in plasma of Kazakh women. According to our data, miR-21-5p can play an important role in the development of $\mathrm{BC}$ in women with these risk factors.

miR-210 is known as a marker of hypoxia during tumor development; and in $\mathrm{BC}$, hypoxia is associated with resistance to therapy and poor prognosis (Camps et al, 2008, Pasculli et al., 2019). Previous studies have shown that dysregulation of circulating miR-210 in BC is associated with tumor presence and lymph node metastasis in patients with HER-2 positive BC (Jung et al., 2012), metastases (Markou et al., 2016, Madhavan et al., 2016) and resistance to chemotherapy (Jung et al, 2012; Shao et al, 2019). In our study, unfortunately, patients with lymph node metastasis were insignificantly represented $(\mathrm{N}=7)$; and there was only one patient with distant metastases. We found no difference in the plasma levels of miR-210-3p in these patients compared to other patients. Instead, we found increased levels of miR-210-3p in patients with poorly differentiated tumor (grade 3 ) compared with patients with moderate differentiated tumor (grade 2). The findings are consistent with the result of a previous study, which showed an increased expression of miR-210 in poorly differentiated tumors compared to well-differentiated 
318 tumors ( $\mathrm{Wu}, 2020)$. Thus, we have shown that circulating miR-210-3p can be a marker of

319 aggressive, poorly differentiated tumors.

320 miR-29 has been shown to have an important role in cancer development (Kwon et al., 2018). In

321 most cancer, miR-29 acts as a tumor suppressor by promoting tumor cell apoptosis, by

322 suppressing DNA methylation of tumor-suppressor genes and by reducing proliferation of

323 tumors and by increasing chemosensitivity (Jiang et al., 2014). In contrast, in BC, miR-29 acts as

324 an oncogene by inhibiting fibrosis and thereby promoting epithelial-mesenchymal transition

325 (Jiang et al., 2014; Wang et al., 2017). In line with this, it has been shown that miR-29 is up-

326

327

328

329

330

331

332

333

334

335

336

337

338

339

340

341

342

343

344

345

346

347

348

349

350

351

352

353

354

355

356

357 regulated both in breast tumors and in the serum of BC patients (Wu et al., 2012; Zhang et al., 2015). But, we found no significant differences in plasma miR-29c-3p concentration between BC patients and controls in the Kazakh population. Instead, we found that level of circulating miR$29 \mathrm{c}-3 \mathrm{p}$ decrease in women (healthy controls) after age 50 compared to younger women. Taking into account the anti-fibrotic activity of miR-29, our data are consistent with the fact that fibrotic processes increase with advancing age (Nho, 2015).

To evaluate the diagnostic effectiveness of potential markers, we performed a ROC analysis. We identified two miRNAs - miR-145-5p and miR-191-5p, which are able to accurately distinguish patients with $\mathrm{BC}$ from healthy women, both individually and in combination. The most effective is their combination model, which showed $97 \%$ accuracy in the separation of two groups -66 out of 68 women were classified correctly. The applicability of the revealed diagnostic capabilities of miRNAs according to clinicopathological parameters is debatable. Although we found a promising combination of miRNA-markers to differentiate $\mathrm{BC}$ patients from healthy people, there are a few suggestions for further research. As the sample size is small, further validations in large cohort are recommended. The majority of BC patients in our study had T2 tumors; so, it is necessary to check whether the data obtained are valid for other stages of tumor progression. Also, it is desirable to investigate whether our miRNAs are reversed in plasma of $\mathrm{BC}$ patients undergoing treatment. In addition, it would be interesting to study the expression of this miRNAs in tumor tissue to test the secretory hypothesis.

\section{Conclusions}

When using spike-in cel-miR-39 as a reference, we obtained doubtful results. Some possible reasons are unequal isolation efficiency of endogenous and spike-in miRNA in each of the two groups, visually undetectable hemolysis, or other unknown factors. Endogenous controls selected according to the literature should be verified in the current study. Based on the results of the analysis of concentration stability as well as taking into account the relative abundance of transcripts, we selected miR-222-3p as the endogenous control for our samples. We revealed three plasma miRNAs (miR-145-5p, miR-191-5p and miR-21-5p) significantly elevated in BC patients compared to control group. ROC analysis showed, that using miR-145$5 p$ and miR-191-5p (both individually and in combination), it is possible to separate BC patients from healthy individuals quite accurately, therefore, these miRNAs should be considered as potential biomarkers for $\mathrm{BC}$ detection in Kazakh population. The inconsistency of some of our 
358

359

360

361

362

363

364

365

366

367

368

369

370

371

372

373

374

375

376

377

378

379

380

381

382

383

384

385

386

387

388

389

390

391

392

393

394

395

396

397

results with published data suggests that it is necessary to verify biomarkers for certain ethnic group. The findings need to be confirmed on a more representative cohort of samples.

\section{References}

Acunzo M, Romano G, Wernicke D, Croce CM. 2015. MicroRNA and cancer - a brief overview. Advances in Biological Regulation, 57: 1-9. DOI: 10.1016/j.jbior.2014.09.013. Adhami M, Haghdoost AA, Sadeghi B, Malekpour Afshar R. 2018. Candidate miRNAs in human breast cancer biomarkers: a systematic review. Breast Cancer, 25(2): 198-205. DOI: 10.1007/s 12282-017-0814-8.

Aggarwal V, Priyanka K, Tuli HS. 2020. Emergence of Circulating MicroRNAs in Breast Cancer as Diagnostic and Therapeutic Efficacy Biomarkers. Molecular Diagnosis \& Therapy, 24(2): 153-173. DOI: 10.1007/s40291-020-00447-w.

Andersen CL, Jensen JL, Orntoft TF. 2004. Normalization of real-time quantitative reverse transcription-PCR data: a model-based variance estimation approach to identify genes suited for normalization, applied to bladder and colon cancer data sets. Cancer Research, 64(15): 5245-50. DOI: 10.1158/0008-5472.CAN-04-0496.

Appierto V, Callari M, Cavadini E, Morelli D, Daidone MG, Tiberio P. 2014. A lipemiaindependent NanoDrop-based score to identify hemolysis in plasma and serum samples. Bioanalysis, 6(9): 1215-26. DOI: 10.4155/bio.13.344.

Camps C, Buffa FM, Colella S, Moore J, Sotiriou C, Sheldon H, Harris AL, Gleadle JM, Ragoussis J. 2008. hsa-miR-210 Is induced by hypoxia and is an independent prognostic factor in breast cancer. Clinical Cancer Research, 14(5): 1340-1348. DOI: 10.1158/1078-0432.CCR07-1755.

Chan M, Liaw CS, Ji SM, Tan HH, Wong CY, Thike AA, Tan PH, Ho GH, Lee ASG. 2013. Identification of circulating microRNA signatures for breast cancer detection. Clinical Cancer Research, 19(16): 4477-87. DOI: 10.1158/1078-0432.CCR-12-3401.

Cui J. 2015. MiR-16 family as potential diagnostic biomarkers for cancer: a systematic review and meta-analysis. International Journal of Clinical and Experimental Medicine, 8(2): 17031714. PMCID: PMC4402746.

Donati S, Ciuffi S, Brandi ML. 2019. Human Circulating miRNAs Real-time qRT-PCR-based Analysis: An Overview of Endogenous Reference Genes Used for Data Normalization.

International Journal of Molecular Sciences, 20(18): 4353. DOI: 10.3390/ijms20184353. Early Breast Cancer Trialists' Collaborative Group (EBCTCG). 2015. Aromatase inhibitors versus tamoxifen in early breast cancer: patient-level meta-analysis of the randomised trials. Lancet, 386(10001): 1341-1352. DOI: 10.1016/S0140-6736(15)61074-1.

Gao X, Xie Z, Wang Z, Cheng K, Liang K, Song Z. 2017. Overexpression of miR-191 Predicts Poor Prognosis and Promotes Proliferation and Invasion in Esophageal Squamous Cell Carcinoma. Yonsei Medical Journal, 58(6): 1101-1110. DOI: 10.3349/ymj.2017.58.6.1101. Glinge C, Clauss S, Boddum K, Jabbari R, Jabbari J, Risgaard B, Tomsits P, Hildebrand B, Kaab S, Wakili R, Jespersen T, Tfelt-Hansen J. 2017. Stability of Circulating Blood-Based 
398 MicroRNAs - Pre-Analytic Methodological Considerations. PLoS One, 12(2): e0167969. DOI: 399 10.1371/journal.pone.0167969.

400 Goksuluk D, Korkmaz S, Zararsiz G, Karaağaoğlu AE. 2016. EasyROC: An Interactive Web401 tool for ROC Curve Analysis Using R Language Environment. The R Journal, 8(2): 213-230. 402 DOI: $10.32614 / \mathrm{RJ}-2016-042$.

403 Grasedieck S, Scholer N, Bommer M, Niess JH, Tumani H, Rouhi A, Bloehdorn J, Liebisch P, 404 Mertens D, Dohner H, Buske C, Langer C, Kuchenbauer F. 2012. Impact of serum storage 405 conditions on microRNA stability. Leukemia, 26: 2414-2444. DOI: 10.1038/leu.2012.106. 406 Greenlee H, DuPont-Reyes MJ, Balneaves LG, Carlson LE, Cohen MR, Deng G, Johnsom JA, 407 Mumber M, Seely D, Zick SM, Boyce LM, Tripathy D. 2017. Clinical practice guidelines on the 408 evidence-based use of integrative therapies during and after breast cancer treatment. $C A: A$ 409 Cancer Journal for Clinicians, 67(3): 194-232. DOI: 10.3322/caac.21397.

410 Guerrero-Zotano AL, Arteaga CL. 2017. Neoadjuvant Trials in ER ${ }^{+}$Breast Cancer: A Tool for 411 Acceleration of Drug Development and Discovery. Cancer Discovery, 7(6): 561-574. DOI:

412 10.1158/2159-8290.CD-17-0228.

413 Hamam R, Hamam D, Alsaleh KA, Kassem M, Zaher W, Alfayez M, Aldahmash A, Alajez NM. 414 2017. Circulating microRNAs in breast cancer: novel diagnostic and prognostic biomarkers. Cell 415 Death \& Disease, 8(9): e3045. DOI: 10.1038/cddis.2017.440.

416 Höfelmann DA, Anjos JC, Ayala AL. 2014. Survival for ten years and prognostic factors for 417 women with breast cancer in Joinville in the State of Santa Catarina, Brazil. Ciencia e Saude 418 Coletiva, 19(6): 1813-24. DOI: 10.1590/1413-81232014196.03062013.

$419 \mathrm{Hu}$ J, Xu J, Wu Y, Chen Q, Zheng W, Lu X, Zhou C, Jiao D. 2015. Identification of microRNA42093 as a functional dysregulated miRNA in triple-negative breast cancer. Tumor Biology, 36(1):

421 251-8. DOI: 10.1007/s13277-014-2611-8.

422 Hu Z, Dong J, Wang LE, Ma H, Liu J, Zhao Y, Tang J, Chen X, Dai J, Wei Q, Zhang C, Shen H. 423 2012. Serum microRNA profiling and breast cancer risk: the use of miR-484/191 as endogenous 424 controls. Carcinogenesis, 33(4): 828-34. DOI: 10.1093/carcin/bgs030.

425 Jansson MD, Lund AH. 2012. MicroRNA and cancer. Molecular Oncology, 6(6): 590-610. DOI: 426 10.1016/j.molonc.2012.09.006.

427 Jeong SH, An YS, Choi JY, Park B, Kang D, Lee MH, Han W, Noh DY, Yoo K-Y, Park SK. 428 2017. Risk Reduction of Breast Cancer by Childbirth, Breastfeeding, and Their Interaction in 429 Korean Women: Heterogeneous Effects Across Menopausal Status, Hormone Receptor Status, 430 and Pathological Subtypes. Journal of Preventive Medicine and Public Health, 50(6): 401-410. 431 DOI: 10.3961/jpmph.17.152.

432 Jiang H, Zhang G, Wu JH, Jiang CP. 2014. Diverse roles of miR-29 in cancer (review).

433 Oncology Reports, 31(4): 1509-1516. DOI: 10.3892/or.2014.3036.

434 Jung EJ, Santarpia L, Kim J, Esteva FJ, Moretti E, Buzdar AU, Leo AD, Le XF, Bast Jr RC, Park 435 ST, Pusztai L, Calin GA. 2012. Plasma microRNA 210 levels correlate with sensitivity to 436 trastuzumab and tumor presence in breast cancer patients. Cancer, 118(10): 2603-2614. DOI: $437 \quad 10.1002 /$ cncr.26565. 
438 Khalis M, Charbotel B, Chajès V, Rihaldi S, Moskal A, Biessy C, Dossus L, Huybrechts I, Fort 439 E, Mellas N, Elfakir S, Charaka H, Nejjari C, Romieu I, Rhazi RE. 2018. Menstrual and 440 reproductive factors and risk of breast cancer: A case-control study in the Fez region, Morocco. 441 PLoS One, 3(1):e0191333. DOI: 10.1371/journal.pone.0191333.

442 Kim J, Oh S, Park S, Ahn S, Choi Y, Kim G, Kim SI, Lee H. 2019. Circulating miR-221 and 443 miR-222 as Potential Biomarkers for Screening of Breast Cancer. Biomedical Science Letters, 444 25: 185-189. DOI: 10.15616/BSL.2019.25.2.185.

445 Kodahl AR, Lyng MB, Binder H, Cold S, Gravgaard K, Knoop AS, Ditzel HJ. 2014. Novel 446 circulating microRNA signature as a potential non-invasive multi-marker test in ER-positive 447 early-stage breast cancer: a case control study. Molecular Oncology, 8(5): 874-83. DOI: 448 10.1016/j.molonc.2014.03.002.

449 Königshoff M, Kramer M, Balsara N, Wilhelm J, Amarie OV, Jahn A, Rose F, Fink L, Seeger 450 W, Schaefer L, Günther A, Eickelberg O. 2009. WNT1-inducible signaling protein-1 mediates 451 pulmonary fibrosis in mice and is upregulated in humans with idiopathic pulmonary fibrosis. 452 Journal of Clinical Investigation, 119(4): 772-87. DOI: 10.1172/JCI33950.

453 Kroh EM, Parkin RK, Mitchell PS, Tewari M. 2010. Analysis of circulating microRNA 454 biomarkers in plasma and serum using quantitative reverse transcription-PCR (qRT-PCR). 455 Methods, 50(4): 298-301. DOI: 10.1016/j.ymeth.2010.01.032.

456 Kwon JJ, Factora TD, Dey S, Kota J. 2018. A Systematic Review of miR-29 in Cancer.

457 Molecular Therapy - Oncolytics, 12: 173-194. DOI: 10.1016/j.omto.2018.12.011.

458 Lee SY, Seo JH. 2018. Current Strategies of Endocrine Therapy in Elderly Patients with Breast 459 Cancer. BioMed Research International, 2018: 6074808. DOI: 10.1155/2018/6074808.

460 Li Q, Qin T, Bi Z, Hong H, Ding L, Chen J, Wu W, Lin X, Fu W, Zheng F, Yao Y, Luo M, Er 461 Saw P, Wulf GM, Xu X, Song E, Yao H, Hu H. 2020. Rac1 activates non-oxidative pentose 462 phosphate pathway to induce chemoresistance of breast cancer. Nature Communications, 11(1): 463 1456. DOI: 10.1038/s41467-020-15308-7.

464 Madhavan D, Peng C, Wallwiener M, Zucknick M, Nees J, Schott S, Rudolph A, Riethdorf S, 465 Trumpp A, Pantel K, Sohn C, Chang-Claude J, Schneeweiss A, Burwinkel B. 2016. Circulating 466 miRNAs with prognostic value in metastatic breast cancer and for early detection of metastasis. 467 Carcinogenesis, 37(5): 461-470. DOI: 10.1093/carcin/bgw008.

468 Mar-Aguilar F, Mendoza-Ramírez JA, Malagón-Santiago I, Espino-Silva PK, Santuario-Facio 469 SK, Ruiz-Flores P, Rodriguez-Padilla C, Resendez-Perez D. 2013. Serum circulating microRNA 470 profiling for identification of potential breast cancer biomarkers. Disease Markers, 34(3): 163-9. 471 DOI: 10.3233/DMA-120957.

472 Markou A, Zavridou M, Sourvinou I, Yousef G, Kounelis S, Malamos N, Georgoulias V, 473 Lianidou E. 2016. Direct Comparison of Metastasis-Related miRNAs Expression Levels in 474 Circulating Tumor Cells, Corresponding Plasma, and Primary Tumors of Breast Cancer Patients. 475 Clinical Chemistry, 62(7): 1002-1011. DOI: 10.1373/clinchem.2015.253716. 
476 McDermott AM, Kerin MJ, Miller N. 2013. Identification and validation of miRNAs as

477 endogenous controls for RQ-PCR in blood specimens for breast cancer studies. PLoS One, 8(12):

478 e83718. DOI: 10.1371/journal.pone.0083718.

479 McDonald ES, Clark AS, Tchou J, Zhang P, Freedman GM. 2016. Clinical Diagnosis and

480 Management of Breast Cancer. The Journal of Nuclear Medicine, 57(Suppl 1): 9S-16S. DOI:

481 10.2967/jnumed.115.157834.

482 McGuire A, Brown JA, Kerin MJ. 2015. Metastatic breast cancer: the potential of miRNA for

483 diagnosis and treatment monitoring. Cancer and Metastasis Reviews, 34(1): 145-55. DOI:

484 10.1007/s10555-015-9551-7.

485 Moo TA, Sanford R, Dang C, Morrow M. 2018. Overview of Breast Cancer Therapy. PET

486 Clinics, 13(3): 339-354. DOI: 10.1016/j.cpet.2018.02.006.

487 Nakshatri H, Anjanappa M, Bhat-Nakshatri P. 2015. Ethnicity-Dependent and -Independent

488 Heterogeneity in Healthy Normal Breast Hierarchy Impacts Tumor Characterization. Scientific

489 Reports, 5: 13526. DOI: 10.1038/srep13526

490 Nassar FJ, Nasr R, Talhouk R. 2017. MicroRNAs as biomarkers for early breast cancer

491 diagnosis, prognosis and therapy prediction. Pharmacology \& Therapeutics, 172: 34-49. DOI:

492 10.1016/j.pharmthera.2016.11.012.

493 Nassar FJ, Talhouk R, Zgheib NK, Tfayli A, El Sabban M, El Saghir NS, Boulos F, Jabbour

494 MN, Chalala C, Boustany M, Kadara H, Zhang Z, Zheng Y, Joyce B, Hou L, Bazarbachi A,

495 Calin G, Nasr R. 2017. MicroRNA Expression in Ethnic Specific Early Stage Breast Cancer: an

496 Integration and Comparative Analysis. Scientific Reports, 7(1): 16829. DOI: 10.1038/s41598-

497 017-16978-y.

498 Nelson HD, Fu R, Cantor A, Pappas M, Daeges M, Humphrey L. 2016. Effectiveness of breast 499 cancer screening: systematic review and meta-analysis to update the 2009 U.S. Preventive

500 Services Task Force Recommendation. Annals of Internal Medicine, 164(4): 244-55. DOI:

501 10.7326/M15-0969.

502 Ng EK, Li R, Shin VY, Jin HC, Leung CP, Ma ES, Pang R, Chua D, Chu KM, Law WL, Law

503 SYK, Poon RTP, Kwong A. 2013. Circulating microRNAs as specific biomarkers for breast

504 cancer detection. PLoS One, 8(1): e53141. DOI: 10.1371/journal.pone.0053141.

505 Nho RS. 2015. Alteration of Aging-Dependent MicroRNAs in Idiopathic Pulmonary Fibrosis.

506 Drug Development Research, 76(7): 343-53. DOI: 10.1002/ddr.21272.

507 Onega T, Goldman LE, Walker RL, Miglioretti DL, Buist DS, Taplin S, Geller BM, Hill DA,

508 Smith-Bindman R. 2016. Facility Mammography Volume in Relation to Breast Cancer

509 Screening Outcomes. Journal of Medical Screening, 23(1): 31-7. DOI:

$51010.1177 / 0969141315595254$.

511 Özdemir BC, Dotto GP. 2017. Racial Differences in Cancer Susceptibility and Survival: More

512 Than the Color of the Skin? Trends in Cancer, 3(3): 181-197. DOI:

513 10.1016/j.trecan.2017.02.002.

514 Pasculli B., Barbano R., Rendina M, Fontana A, Copetti M, Mazza T, Valori VM, Morritti M,

515 Maiello E, Graziano P, Murgo R, Fazio VM, Esteller M, Parrella P. 2019. Hsa-miR-210-3p 
516 expression in breast cancer and its putative association with worse outcome in patients treated 517 with Docetaxel. Scientific Reports, 9: 14913. DOI: 10.1038/s41598-019-51581-3.

518 Phi XA, Tagliafico A, Houssami N, Greuter MJW, de Bock GH. 2018. Digital breast

519 tomosynthesis for breast cancer screening and diagnosis in women with dense breasts - a

520 systematic review and meta-analysis. BMC Cancer, 18(1): 380. DOI: 10.1186/s12885-018-4263-

5213.

522 Pizzamiglio S, Zanutto S, Ciniselli CM, Belfiore A, Bottelli S, Gariboldi M, Verderio P. 2017. A 523 methodological procedure for evaluating the impact of hemolysis on circulating microRNAs.

524 Oncology Letters, 13(1): 315-320. DOI: 10.3892/ol.2016.5452.

525 Potosky AL, O'Neill SC, Isaacs C, Tsai HT, Chao C, Liu C, Ekezue BF, Selvam N, Kessler LG, 526 Zhou Y, Schwartz MD. 2015. Population-based study of the effect of gene expression profiling

527 on adjuvant chemotherapy use in breast cancer patients under the age of 65 years. Cancer, 528 121(22): 4062-70. DOI: 10.1002/cncr.29621.

529 Qiu Y-F, Wang M-X, Meng L-N, Zhang R, Wang W. 2018. MiR-21 regulates proliferation and 530 apoptosis of oral cancer cells through TNF- $\alpha$. European Review for Medical and

531 Pharmacological Science, 22(22): 7735-7741. DOI: 10.26355/eurrev_201811_16395.

532 Sachdeva M, Zhu S, Wu F, Wu H, Walia V, Kumar S, Elble R, Watabe K, Mo Y-Y. 2009. P53

533 represses c-Myc through induction of the tumor suppressor miR-145. Proceedings of the

534 National Academy of Sciences of the United States of America, 106(9): 3207-12. DOI:

535 10.1073/pnas.0808042106.

536 Schwarzenbach H, da Silva AM, Calin G, Pantel K. 2015. Data Normalization Strategies for

537 MicroRNA Quantification. Clinical Chemistry, 61(11): 1333-42. DOI:

538 10.1373/clinchem.2015.239459.

539 Schwarzenbach H. 2017. Clinical Relevance of Circulating, Cell-Free and Exosomal microRNAs

540 in Plasma and Serum of Breast Cancer Patients. Oncology Research and Treatment, 40(7-8):

541 423-429. DOI: 10.1159/000478019.

542 Shao B, Wang X, Zhang L, Li D, Liu X, Song G, Cao H, Zhu J, Li H. 2019. Plasma microRNAs

543 Predict Chemoresistance in Patients With Metastatic Breast Cancer. Technology in Cancer

544 Research and Treatment, 18: 1533033819828709. DOI: 10.1177/1533033819828709.

545 Song J, Ouyang Y, Che J, Li X, Zhao Y, Yang K, Zhao X, Chen Y, Fan C, Yuan W. 2017.

546 Potential Value of miR-221/222 as Diagnostic, Prognostic, and Therapeutic Biomarkers for

547 Diseases. Frontiers in Immunology, 8: 56. DOI: 10.3389/fimmu.2017.00056.

548 Sourvinou IS, Markou A, Lianidou ES. 2013. Quantification of circulating miRNAs in plasma:

549 effect of preanalytical and analytical parameters on their isolation and stability. The Journal of

550 Molecular Diagnostics, 15(6): 827-34. DOI: 10.1016/j.jmoldx.2013.07.005.

551 Stückrath I, Rack B, Janni W, Jäger B, Pantel K, Schwarzenbach H. 2015. Aberrant plasma

552 levels of circulating miR-16, miR-107, miR-130a and miR-146a are associated with lymph node

553 metastasis and receptor status of breast cancer patients. Oncotarget, 6(15): 13387-13401.

554 DOI:10.18632/oncotarget.3874. 
555 Sun Z, Shi K, Yang S, Liu J, Zhou Q, Wang G, Song J, Li Z, Zhang Z, Yuan W. 2018. Effect of 556 exosomal miRNA on cancer biology and clinical applications. Molecular Cancer, 17(1): 147.

557 DOI: 10.1186/s12943-018-0897-7.

558 Tay JW, James I, Hughes QW, Tiao JY, Baker RI. 2017. Identification of reference miRNAs in

559 plasma useful for the study of oestrogen-responsive miRNAs associated with acquired Protein $\mathrm{S}$ 560 deficiency in pregnancy. BMC Research Notes, 10(1): 312. DOI: 10.1186/s13104-017-2636-3.

561 Usmani A, Shoro AA, Shirazi B, Memon Z, Hussain M. 2017. MiR-16: A novel hereditary

562 marker in breast cancer and their offspring. Journal of Pakistan Medical Association, 67(3): 446563 450. PMID: 28303998.

564 Vandesompele J, De Preter K, Pattyn F, Poppe B, Van Roy N, De Paepe A, Speleman F. 2002.

565 Accurate normalization of real-time quantitative RT-PCR data by geometric averaging of

566 multiple internal control genes. Genome Biology, 3(7): 34.1-34.11. DOI: 10.1186/gb-2002-3-7567 research0034.

568 Wang H, An X, Yu H, Zhang S, Tang B, Zhang X, Li Z. 2017. MiR-29b/TET1/ZEB2 signaling 569 axis regulates metastatic properties and epithelial-mesenchymal transition in breast cancer cells.

570 Oncotarget, 8(60): 102119-102133. DOI: 10.18632/oncotarget.22183.

571 Wang H, Tan Z, Hu H, Liu H, Wu T, Zheng C, Wang X, Luo Z, Wang J, Liu S, Lu Z, Tu J.

572 2019. MicroRNA-21 promotes breast cancer proliferation and metastasis by targeting LZTFL1.

573 BMC Cancer, 19(1): 738. DOI: 10.1186/s12885-019-5951-3.

574 Wang L. 2017. Early Diagnosis of Breast Cancer. Sensors (Basel), 17(7): 1572. DOI:

$57510.3390 / \mathrm{s} 17071572$.

576 Wu Q, Wang C, Lu Z, Guo L, Ge Q. 2012. Analysis of serum genome-wide microRNAs for

577 breast cancer detection. Clinica Chimica Acta, 413(13-14): 1058-1065. DOI:

578 10.1016/j.cca.2012.02.016.

579 Wu SM, Tsai WS, Chiang SF, Lai YH, Ma CP, Wang JH, Lin J, Lu P-S, Yang C-Y, Tan BCM, 580 Liu H. 2020. Comprehensive transcriptome profiling of Taiwanese colorectal cancer implicates 581 an ethnic basis for pathogenesis. Scientific Reports, 10(1): 4526. DOI: 10.1038/s41598-020-

582 61273-y.

$583 \mathrm{Wu}$ X. 2020. Expressions of miR-21 and miR-210 in Breast Cancer and Their Predictive Values 584 for Prognosis. Iranian Journal of Public Health, 49(1):21-29. PMID: 32309220.

585 Zhao H, Shen J, Medico L, Wang D, Ambrosone CB, Liu S. 2010. A pilot study of circulating 586 miRNAs as potential biomarkers of early stage breast cancer. PLoS One, 5(10): e13735. DOI:

587 10.1371/journal.pone.0013735.

588 Zhang L, Xu Y, Jin X, Wang Z, Wu Y, Zhao D, Chen G, Li D, Wang X, Cao H, Xie Y, Liang Z. 589 2015. A circulating miRNA signature as a diagnostic biomarker for non-invasive early detection 590 of breast cancer. Breast Cancer Res Treat, 154(2): 423-434. DOI: 10.1007/s10549-015-3591-0.

591 Zhang X, Wu M, Chong QY, Zhang W, Qian P, Yan H, Qian W, Zhang M, Lobie PE, Zhu T.

592 2018. Amplification of hsa-miR-191/425 locus promotes breast cancer proliferation and

593 metastasis by targeting DICER1. Carcinogenesis, 39(12): 1506-1516. DOI:

594 10.1093/carcin/bgy102. 
595 Zhong P, Chen X, Guo R, Chen X, Chen Z, Wei C, Li Y, Wang W, Zhou Y, Qin L. 2020. Folic 596 Acid-Modified Nanoerythrocyte for Codelivery of Paclitaxel and Tariquidar to Overcome Breast 597 Cancer Multidrug Resistance. Molecular Pharmaceutics, 17(4): 1114-1126. DOI:

598 10.1021/acs.molpharmaceut.9b01148.

599 Zununi Vahed S, Barzegari A, Rahbar Saadat Y, Mohammadi S, Samadi N. 2016. A microRNA 600 isolation method from clinical samples. Bioimpacts, 6(1): 25-31. DOI: 10.15171/bi.2016.04. 
Figure 1

Selection of endogenous control

(A) Results from NormFinder: intergroup (bars) and intragroup (whiskers) variation plot and stability value (SV), calculated on their basis; (B) Average expression stability values of remaining control candidates during stepwise exclusion of the least stable control candidate, obtained from GeNorm. 
A

- Control $\square \mathrm{BC}$

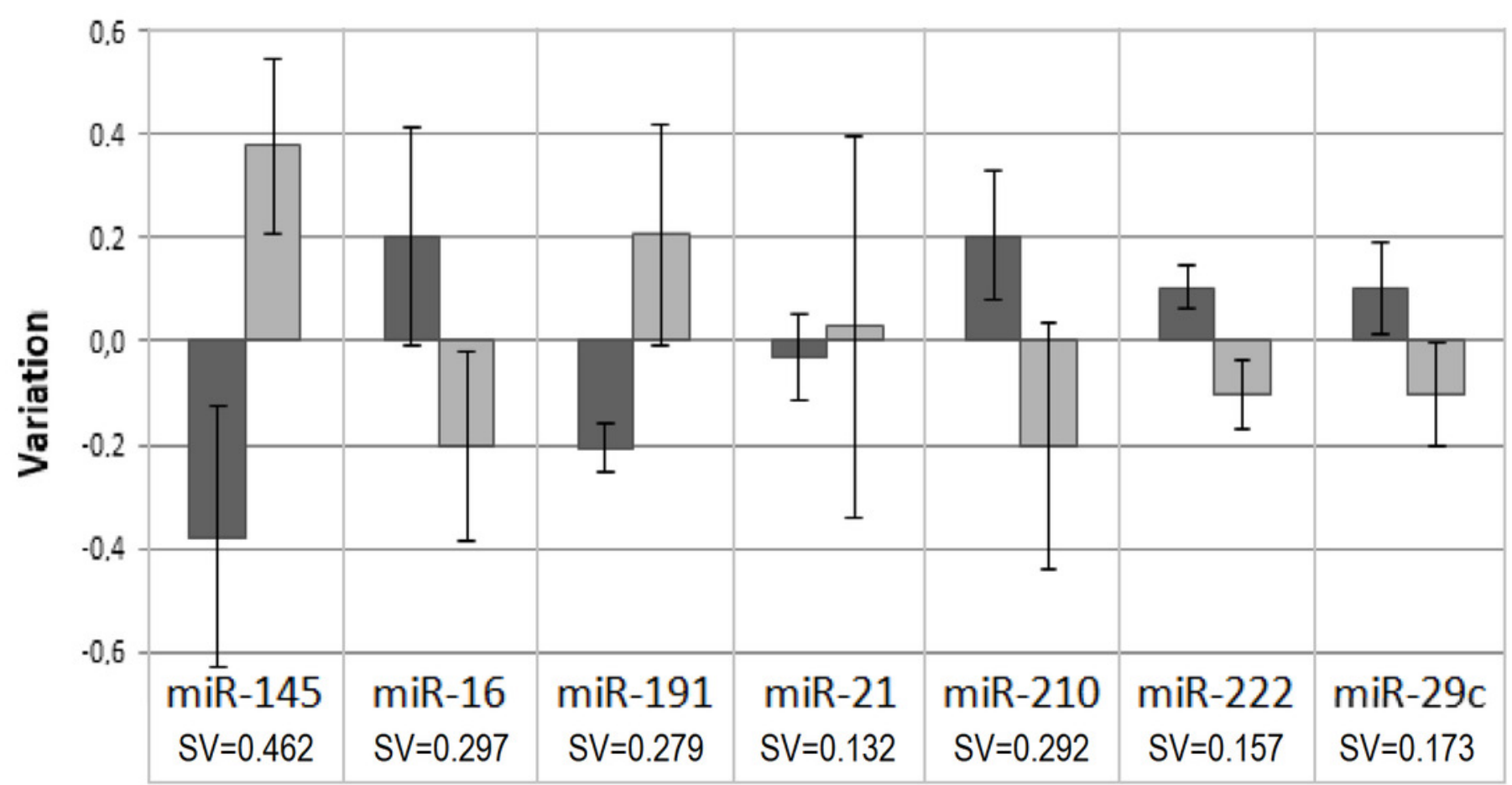

B

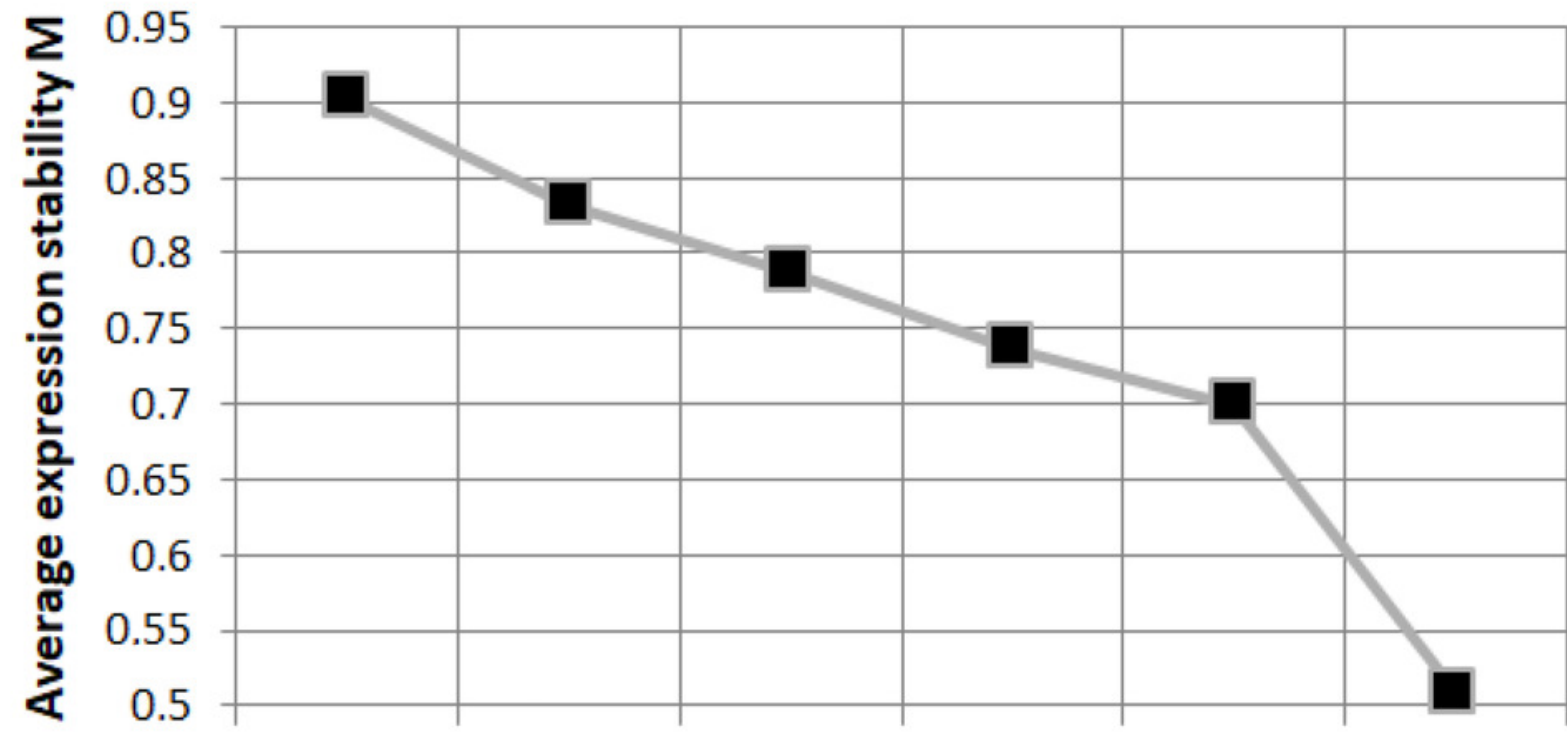

miR-145 miR-21 miR-191 miR-16 miR-210 miR-222 $\operatorname{miR}-29 c$

<::::: Least stable genes Most stable genes ::::> 
Figure 2

Differences in $\Delta \mathrm{Ct}$ between $\mathrm{BC}$ patients and control group

(A) Data are normalized to the spike-in control cel-miR-39; (B) Data are normalized to the endogenous control miR-222-3p.

A

A
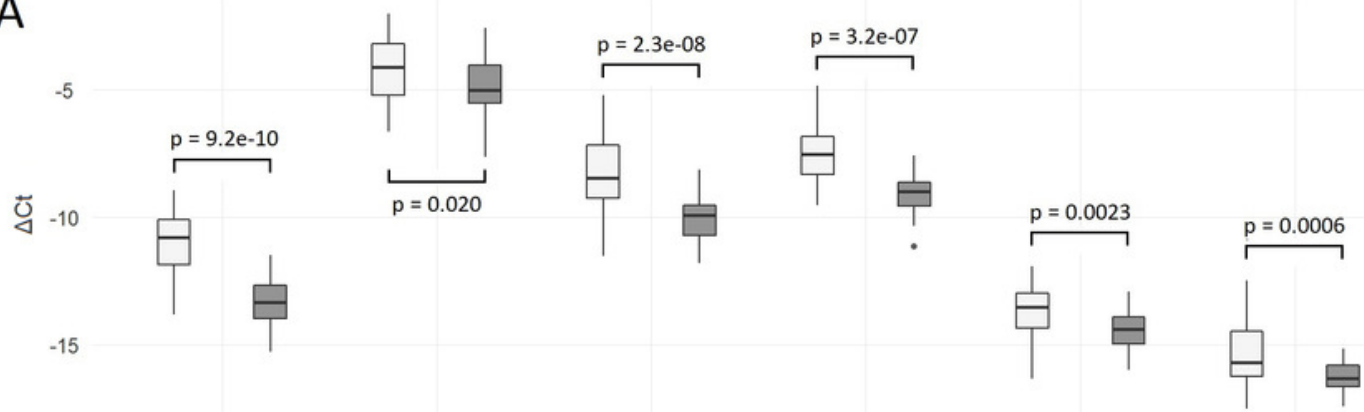

miR-145-5p

miR-16-5p

miR-191-5p

miR-21-5p

miR-210-3p

miR-29c-3p

miR-222-3p

Groups 帛 $\mathrm{BC}$ 官 Control

B 8

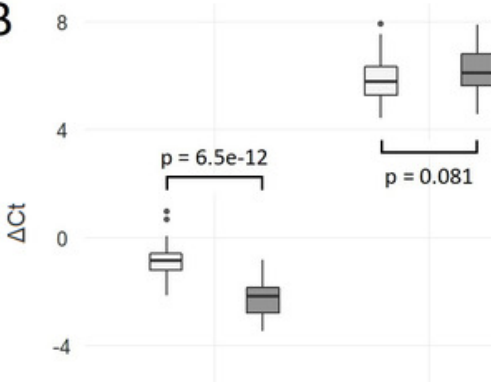

miR-145-5p

miR-16-5p
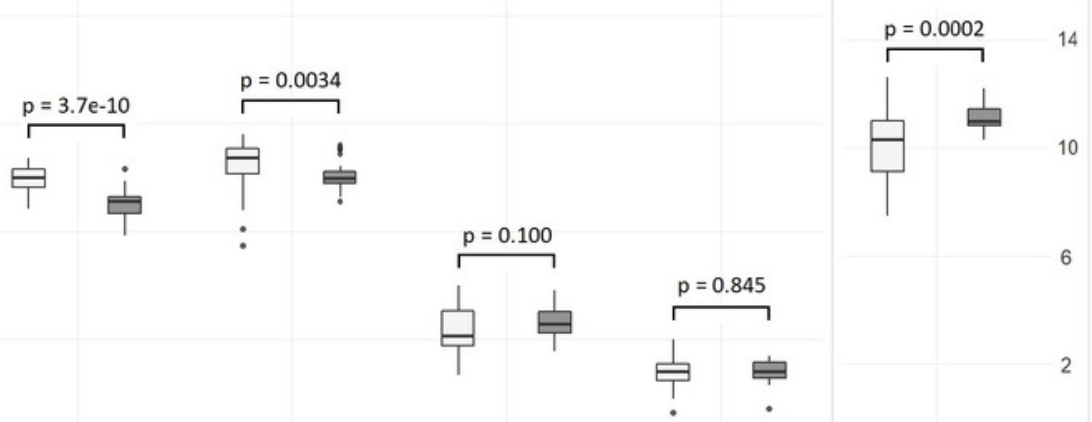

cel-miR-39 


\section{Figure 3}

ROC plots for miRNAs, showing significant differences in plasma levels between BC patients group and control group

(A) miR-145-5p, miR-191-5p and miR-21-5p, normalized to cel-miR-39; (B) miR-16-5p, miR-210-3p, miR-222-3p and miR-29c-3p, normalized to cel-miR-39; (C) miR-145-5p, miR-191-5p and miR-21-5p, normalized to miR-222-3p; (D) Combination of miR-145-5p and miR-191-5p, normalized to miR-222-3p. 

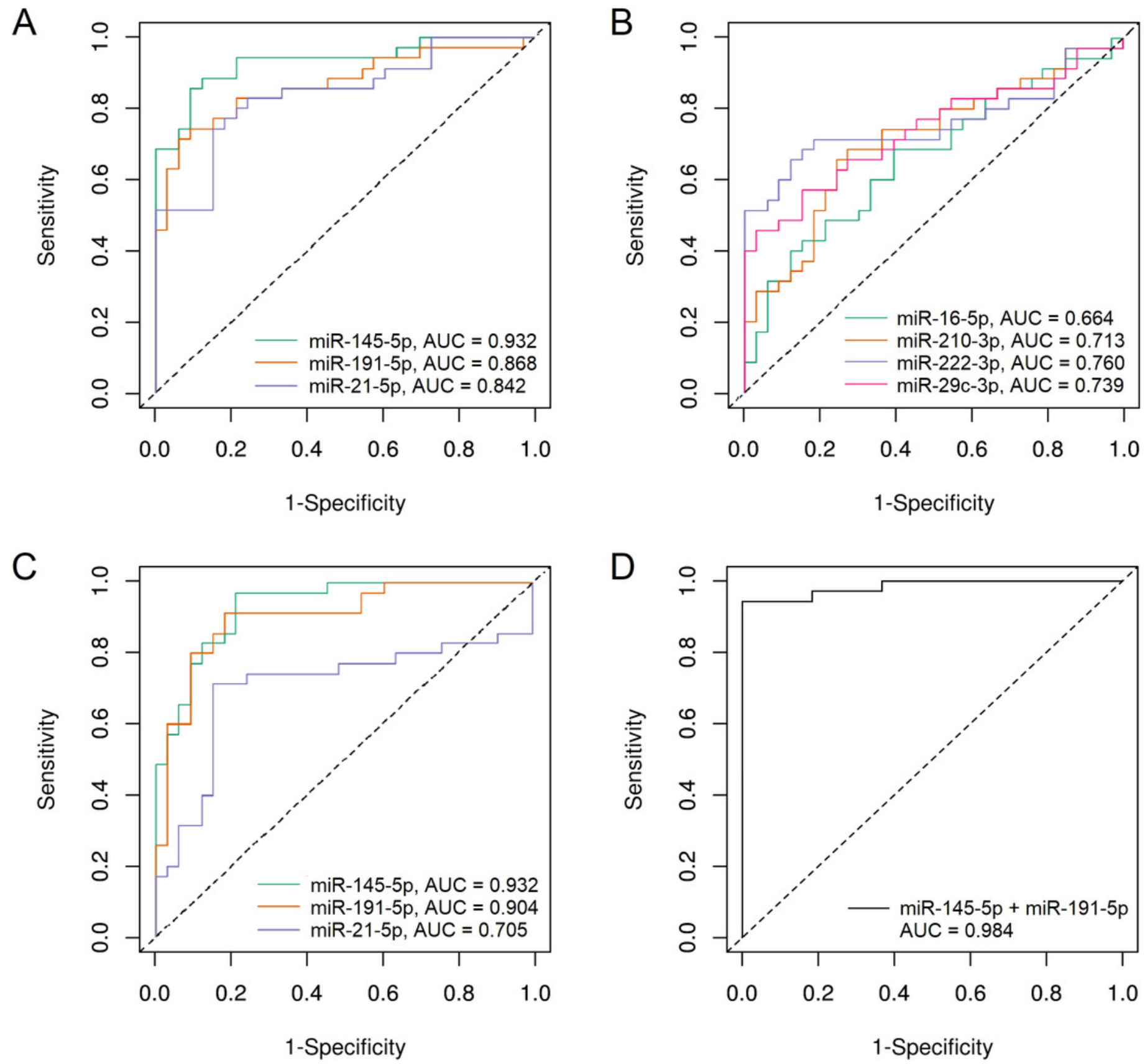
Table $\mathbf{1}$ (on next page)

Clinicopathological characteristics of BC patients group and control group 


\begin{tabular}{|l|l|l|}
\hline Characteristics & BC patients group & Control group \\
\hline ER- / ER+ & $8 / 27$ & - \\
\hline PR- / PR+ & $10 / 25$ & - \\
\hline HER2- / HER2+ & $27 / 7$ & - \\
\hline Tumor size: T1 / T2 / T3 / T4 & $4 / 28 / 2 / 1$ & - \\
\hline Lymph node: Nx / N0 / N1-3 & $5 / 23 / 7$ & - \\
\hline Metastases: no / yes & $34 / 1$ & - \\
\hline Ki-67: $<20 \%$ / $\geq 20 \%$ & $17 / 18$ & - \\
\hline Tumor grade: G1 / G2 / G3 & $1 / 28 / 6$ & - \\
\hline Menarche age: early $(\leq 14) /$ late $(>14)$ & $27 / 8$ & $16 / 17$ \\
\hline Menopausal status: pre- / post & $14 / 21$ & $14 / 19$ \\
\hline Age of first birth: $\leq 22 / \geq 23$ & $17 / 16$ & $18 / 15$ \\
\hline Number of children: 0 / $\leq 2 / \geq 3$ & $2 / 13 / 20$ & $0 / 13 / 20$ \\
\hline Number of unsuccessful pregnancies: $0 / 1 / \geq 2$ & $11 / 10 / 14$ & $8 / 9 / 16$ \\
\hline Family history of cancer: no / yes & $27 / 8$ & $24 / 9$ \\
\hline Alcohol consumption: no / yes & $31 / 4$ & $26 / 7$ \\
\hline
\end{tabular}




\section{Table 2 (on next page)}

Cycle threshold values $(\mathrm{Ct})$ and comparative statistics of studied miRNAs between the $\mathrm{BC}$ patients group and control group 


\begin{tabular}{|c|c|c|c|c|c|c|c|c|c|c|}
\hline \multirow[t]{2}{*}{ miRNA } & \multirow{2}{*}{$\begin{array}{l}\mathrm{BC} \\
\mathrm{Ct} \text { mean } \\
\pm \mathrm{SD}\end{array}$} & \multirow{2}{*}{$\begin{array}{l}\text { Control } \\
\text { Ct mean } \\
\pm \mathrm{SD}\end{array}$} & \multicolumn{4}{|c|}{ cel-miR-39 normalization } & \multicolumn{4}{|c|}{ miR-222-3p normalization } \\
\hline & & & $\begin{array}{l}\mathrm{BC} \\
\Delta \mathrm{Ct} \\
\text { mean } \pm \\
\mathrm{SE}\end{array}$ & $\begin{array}{l}\text { Control } \\
\Delta \mathrm{Ct} \\
\text { mean } \pm \\
\mathrm{SE}\end{array}$ & $\begin{array}{l}\Delta \Delta \mathrm{Ct} \\
(95 \% \mathrm{CI}) \\
\text { log2 fold } \\
\text { change }\end{array}$ & $P$ value & $\begin{array}{l}\mathrm{BC} \\
\Delta \mathrm{Ct} \\
\text { mean } \pm \\
\mathrm{SE}\end{array}$ & $\begin{array}{l}\text { Control } \\
\Delta \mathrm{Ct} \\
\text { mean } \pm \\
\mathrm{SE}\end{array}$ & $\begin{array}{l}\Delta \Delta \mathrm{Ct} \\
(95 \% \mathrm{CI}), \\
\log _{2} \text { fold } \\
\text { change }\end{array}$ & $\mathrm{P}$ value \\
\hline miR-145-5p & $\begin{array}{l}29.52 \pm \\
1.52\end{array}$ & $\begin{array}{l}32.41 \pm \\
1.19\end{array}$ & $\begin{array}{l}-10.94 \pm \\
0.21\end{array}$ & $\begin{array}{l}-13.30 \pm \\
0.16\end{array}$ & $\begin{array}{l}2.36 \\
(1.84 ; 2.88)\end{array}$ & $9.2 \mathrm{e}-10$ & $\begin{array}{l}-0.84 \pm \\
0.11\end{array}$ & $\begin{array}{l}-2.22 \pm \\
0.12\end{array}$ & $\begin{array}{l}1.38 \\
(1.06 ; 1.72)\end{array}$ & $6.5 \mathrm{e}-12$ \\
\hline $\operatorname{miR}-16-5 p$ & $\begin{array}{l}22.72 \pm \\
1.70\end{array}$ & $\begin{array}{l}23.94 \pm \\
1.46\end{array}$ & $\begin{array}{l}-4.14 \pm \\
0.20\end{array}$ & $\begin{array}{l}-4.83 \pm \\
0.18\end{array}$ & $\begin{array}{l}0.69 \\
(0.15 ; 1.23)\end{array}$ & 0.020 & $\begin{array}{l}5.96 \pm \\
0.15\end{array}$ & $\begin{array}{l}6.25 \pm \\
0.14\end{array}$ & $\begin{array}{l}-0.29 \\
(-0.69 ; 0.12)\end{array}$ & 0.081 \\
\hline miR-191-5p & $\begin{array}{l}26.76 \pm \\
1.76\end{array}$ & $\begin{array}{l}29.17 \pm \\
1.17\end{array}$ & $\begin{array}{l}-8.18 \pm \\
0.26\end{array}$ & $\begin{array}{l}-10.05 \pm \\
0.14\end{array}$ & $\begin{array}{l}1.87 \\
(1.28 ; 2.46)\end{array}$ & $2.3 \mathrm{e}-08$ & $\begin{array}{l}1.92 \pm \\
0.08\end{array}$ & $\begin{array}{l}1.02 \pm \\
0.09\end{array}$ & $\begin{array}{l}0.89 \\
(0.66 ; 1.13)\end{array}$ & $3.7 \mathrm{e}-10$ \\
\hline miR-21-5p & $\begin{array}{l}26.24 \pm \\
1.84\end{array}$ & $\begin{array}{l}28.13 \pm \\
1.10\end{array}$ & $\begin{array}{l}-7.66 \pm \\
0.18\end{array}$ & $\begin{array}{l}-9.02 \pm \\
0.14\end{array}$ & $\begin{array}{l}1.35 \\
(0.89 ; 1.82)\end{array}$ & $3.2 \mathrm{e}-07$ & $\begin{array}{l}2.44 \pm \\
1.17\end{array}$ & $\begin{array}{l}2.06 \pm \\
0.09\end{array}$ & $\begin{array}{l}0.38 \\
(-0.04 ; 0.76)\end{array}$ & 0.0034 \\
\hline miR-210-3p & $\begin{array}{l}32.31 \pm \\
1.38\end{array}$ & $\begin{array}{l}33.53 \pm \\
1.09\end{array}$ & $\begin{array}{l}-13.73 \pm \\
0.17\end{array}$ & $\begin{array}{l}-14.42 \pm \\
0.15\end{array}$ & $\begin{array}{l}0.69 \\
(0.24 ; 1.14)\end{array}$ & 0.0023 & $\begin{array}{l}-3.63 \pm \\
0.15\end{array}$ & $\begin{array}{l}-3.35 \pm \\
0.11\end{array}$ & $\begin{array}{l}-0.29 \\
(-0.65 ; 0.08)\end{array}$ & 0.100 \\
\hline miR-29c-3p & $\begin{array}{l}33.87 \pm \\
1.81 \\
\end{array}$ & $\begin{array}{l}35.38 \pm \\
0.96 \\
\end{array}$ & $\begin{array}{l}-15.29 \pm \\
0.22\end{array}$ & $\begin{array}{l}-16.27 \pm \\
0.10\end{array}$ & $\begin{array}{l}0.98 \\
(0.49 ; 1.47)\end{array}$ & 0.0002 & $\begin{array}{l}-5.19 \pm \\
0.10\end{array}$ & $\begin{array}{l}-5.19 \pm \\
0.07\end{array}$ & $\begin{array}{l}0.01 \\
(-0.24 ; 0.25)\end{array}$ & 0.845 \\
\hline miR-222-3p & $\begin{array}{l}28.68 \pm \\
1.52 \\
\end{array}$ & $\begin{array}{l}30.19 \pm \\
0.84\end{array}$ & $\begin{array}{l}-10.10 \pm \\
0.20\end{array}$ & $\begin{array}{l}-11.08 \pm \\
0.08\end{array}$ & $\begin{array}{l}0.98 \\
(0.53 ; 1.42)\end{array}$ & 0.0006 & - & - & - & - \\
\hline cel-miR-39 & $\begin{array}{l}18.58 \pm \\
1.10 \\
\end{array}$ & $\begin{array}{l}19.11 \pm \\
0.67 \\
\end{array}$ & - & - & - & - & $\begin{array}{l}-10.10 \pm \\
0.20 \\
\end{array}$ & $\begin{array}{l}-11.08 \pm \\
0.08 \\
\end{array}$ & $\begin{array}{l}-0.98 \\
(-1.42 ;-0.53)\end{array}$ & 0.0002 \\
\hline
\end{tabular}

1 


\section{Table 3 (on next page)}

$\mathrm{P}$ values for $\Delta \mathrm{Ct}$ comparisons between groups with different clinicopathological characteristics, after normalization to miR-222-3p 


\begin{tabular}{|l|c|c|c|c|c|c|}
\hline \multicolumn{1}{|c|}{ Clinicopathological characteristics } & $\begin{array}{c}\text { miR-145- } \\
5 \mathrm{p}\end{array}$ & $\begin{array}{c}\text { miR-16- } \\
5 \mathrm{p}\end{array}$ & $\begin{array}{c}\text { miR-191- } \\
5 \mathrm{p}\end{array}$ & $\begin{array}{c}\text { miR-21- } \\
5 \mathrm{p}\end{array}$ & $\begin{array}{c}\text { miR-210- } \\
3 \mathrm{p}\end{array}$ & $\begin{array}{c}\text { miR-29c- } \\
3 \mathrm{p}\end{array}$ \\
\hline BC patients group & & & & & & \\
\hline ER- vs ER+ & 0.630 & 0.714 & 0.862 & 0.269 & 0.832 & 0.428 \\
\hline PR- vs PR+ & 0.287 & 0.627 & 0.553 & 0.339 & 0.577 & 0.122 \\
\hline HER2- vs HER2+ & $\mathbf{0 . 0 4 3}$ & 0.559 & $\mathbf{0 . 0 0 6}$ & 0.379 & 0.191 & 0.771 \\
\hline N0 vs N1-3 & 0.086 & 0.441 & 0.190 & 0.246 & 0.810 & 0.360 \\
\hline Ki-67 $<20 \%$ vs $\geq 20 \%$ & 0.096 & 0.134 & 0.089 & $\mathbf{0 . 0 0 3}$ & 0.708 & 0.405 \\
\hline Tumor grade: G2 vs G3 & $\mathbf{0 . 0 3 3}$ & 0.066 & 0.644 & 0.297 & $\mathbf{0 . 0 0 7}$ & 0.676 \\
\hline Age: $<50$ vs. $\geq 50$ & 0.257 & 0.987 & 0.906 & 0.371 & 0.191 & 0.749 \\
\hline Menarche age: $\leq 14$ vs $>14$ & $\mathbf{0 . 0 0 9}$ & 0.743 & 0.166 & $\mathbf{0 . 0 2 2}$ & 0.802 & 0.862 \\
\hline Menopausal status: pre- vs post & 0.096 & 0.908 & 0.517 & 0.249 & 0.118 & 0.881 \\
\hline Age of first birth: $\leq 22$ vs $>22$ & 0.063 & 0.683 & 0.345 & 0.873 & 0.102 & 0.276 \\
\hline Number of children: $\leq 2$ vs $>2$ & 0.987 & 0.347 & 0.139 & 0.107 & 0.521 & 0.099 \\
\hline Unsuccessful pregnancies: 0 vs $>0$ & 0.316 & 0.061 & 0.713 & 0.163 & 0.300 & 0.099 \\
\hline Family history of cancer: no vs yes & 0.576 & 0.499 & 0.550 & 0.143 & 0.286 & 0.143 \\
\hline Alcohol consumption: no vs yes & 0.093 & 0.378 & 0.233 & 0.745 & 0.379 & 0.565 \\
\hline Control group & & & & & & \\
\hline Age: $<50$ vs. $\geq 50$ & 0.501 & 0.986 & 0.102 & 0.842 & 0.137 & $\mathbf{0 . 0 0 8}$ \\
\hline Menarche age: $\leq 14$ vs $>14$ & 0.402 & 0.118 & 0.087 & 0.581 & 0.276 & 0.402 \\
\hline Menopausal status: pre- vs post- & 0.240 & 0.186 & 0.872 & 0.553 & 0.815 & 0.114 \\
\hline Age of first birth: $\leq 22$ vs $>22$ & 0.486 & 0.929 & 0.166 & 0.442 & 0.401 & 0.901 \\
\hline Number of children: $\leq 2$ vs $>2$ & 0.478 & 0.316 & 0.392 & $\mathbf{0 . 0 1 1}$ & 0.235 & 0.730 \\
\hline Unsuccessful pregnancies: 0 vs $>0$ & 0.696 & 0.272 & 0.886 & 0.067 & 0.127 & 0.726 \\
\hline Family history of cancer: no vs yes & 0.796 & 0.438 & $\mathbf{0 . 0 2 9}$ & 0.592 & 0.179 & 0.564 \\
\hline Alcohol consumption: no vs yes & 0.352 & 0.215 & 0.780 & 0.682 & 0.352 & 0.249 \\
\hline
\end{tabular}




\section{Table 4(on next page)}

ROC analysis results for potential markers and their combinations 


\begin{tabular}{|c|c|c|c|c|c|c|c|c|c|c|c|}
\hline \multirow[t]{2}{*}{ Classes } & \multirow{2}{*}{$\begin{array}{l}\text { Potential } \\
\text { markers/ } \\
\text { combinations }\end{array}$} & \multicolumn{5}{|c|}{ cel-miR-39 normalization } & \multicolumn{5}{|c|}{ miR-222-3p normalization } \\
\hline & & $\stackrel{\circlearrowright}{己}$ & 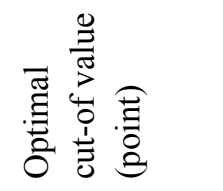 & 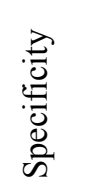 & : & 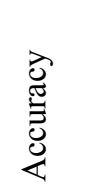 & $\stackrel{\circlearrowright}{己}$ & 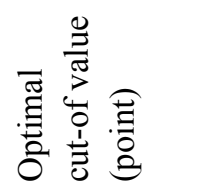 & 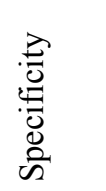 & 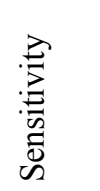 & 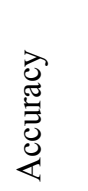 \\
\hline \multirow[t]{11}{*}{ Controls vs BC patients } & $\operatorname{miR}-145-5 p$ & 0.932 & $0.535(-12.17)$ & 0.857 & 0.909 & 0.882 & 0.932 & $0.32(-1.77)$ & 0.788 & 0.971 & 0.882 \\
\hline & miR-16-5p & 0.664 & $0.51(-4.45)$ & 0.606 & 0.686 & 0.647 & - & - & - & - & - \\
\hline & miR-191-5p & 0.868 & $0.60(-9.00)$ & 0.939 & 0.714 & 0.824 & 0.904 & $0.421(1.37)$ & 0.818 & 0.914 & 0.868 \\
\hline & miR-21-5p & 0.842 & $0.58(-8.21)$ & 0.848 & 0.743 & 0.794 & 0.705 & $0.54(2.42)$ & 0.848 & 0.714 & 0.779 \\
\hline & $\operatorname{miR}-210-3 p$ & 0.713 & $0.55(-13.86)$ & 0.758 & 0.657 & 0.706 & - & - & - & - & - \\
\hline & miR-222-3p & 0.760 & $0.549(-10.57)$ & 0.879 & 0.657 & 0.765 & - & - & - & - & - \\
\hline & $\operatorname{miR}-29 c-3 p$ & 0.739 & $0.68(-15.23)$ & 0.970 & 0.457 & 0.706 & - & - & - & - & - \\
\hline & $\begin{array}{l}\operatorname{miR}-145-5 p+ \\
\operatorname{miR}-191-5 p\end{array}$ & 0.930 & 0.52 & 0.879 & 0.886 & 0.882 & 0.984 & 0.72 & 1.000 & 0.943 & 0.971 \\
\hline & $\begin{array}{l}\operatorname{miR}-145-5 p+ \\
\operatorname{miR}-21-5 p\end{array}$ & 0.936 & 0.44 & 0.818 & 0.943 & 0.882 & 0.932 & 0.44 & 0.818 & 0.914 & 0.868 \\
\hline & $\begin{array}{l}\operatorname{miR}-191-5 p+ \\
\operatorname{miR}-21-5 p\end{array}$ & 0.875 & 0.36 & 0.697 & 0.914 & 0.809 & 0.919 & 0.53 & 0.879 & 0.857 & 0.868 \\
\hline & $\begin{array}{l}\text { miR-145-5p+ } \\
\text { miR-191-5p }+ \\
\text { miR-21-5p }\end{array}$ & 0.933 & 0.605 & 0.939 & 0.829 & 0.882 & 0.984 & 0.72 & 1.000 & 0.943 & 0.971 \\
\hline \multirow[t]{2}{*}{ HER2- vs HER2+ } & miR-145-5p & - & - & - & - & - & 0.751 & $0.15(-0.98)$ & 0.481 & 1.000 & 0.588 \\
\hline & miR-191-5p & - & - & - & - & - & 0.831 & 0.147 (1.98) & 0.667 & 1.000 & 0.735 \\
\hline Ki-67: $<20 \%$ vs $\geq 20 \%$ & $\operatorname{miR}-21-5 p$ & - & - & - & - & - & 0.791 & $0.506(2.55)$ & 0.706 & 0.944 & 0.829 \\
\hline \multirow[t]{2}{*}{ Tumor grade: G2 vs G3 } & miR-145-5p & - & - & - & - & - & 0.780 & $0.32(-0.25)$ & 0.667 & 0.964 & 0.912 \\
\hline & miR-210-3p & - & - & - & - & - & 0.845 & $0.10(-3.73)$ & 1.000 & 0.679 & 0.735 \\
\hline
\end{tabular}

1 